\title{
Facial nerve function and hearing after microsurgical removal of sporadic vestibular schwannomas in a population-based cohort
}

\author{
Ismail Taha ${ }^{1,2}$ • Antti Hyvärinen ${ }^{3}$ • Antti Ranta ${ }^{1}$ • Olli-Pekka Kämäräinen ${ }^{1}$ • Jukka Huttunen ${ }^{1}$ • Esa Mervaala ${ }^{4}$. \\ Heikki Löppönen ${ }^{3} \cdot$ Tuomas Rauramaa $^{5}$ • Antti Ronkainen ${ }^{6}$ • Juha E. Jääskeläinen ${ }^{1}$ • Arto Immonen ${ }^{1} \cdot$ Nils Danner $^{1}$ (D)
}

Received: 27 June 2019 / Accepted: 29 August 2019/Published online: 7 September 2019

(C) The Author(s) 2019

\begin{abstract}
Background Vestibular schwannoma (VS) is a benign tumor originating from the vestibulocochlear nerve. The optimal treatment strategy is debated, since surgery may result in iatrogenic facial nerve injury. We report the results of VS surgery in a populationbased unselected cohort in a center with access to Cyber Knife (CK) radiosurgery.

Methods We reviewed 117 consecutive operations and found 95 patients who had their primary operation due to vestibular schwannoma between 2001 and 2017. Facial nerve function was evaluated with the House-Brackmann (HB) scale and hearing with the EU classification.

Results The population consisted of 37 males and 58 females with a median age of 54 years (range 19-79). One year after surgery $67 \%$ of patients had a good outcome (HB 1-2). The rate of good outcome was $90 \%$ if no facial nerve damage was observed during intraoperative monitoring, the size of the tumor was under $30 \mathrm{~mm}$ and no hydrocephalus was present. During the study period, the treatment strategy changed from total to near-total resection after the introduction of CK radiosurgery, which could be used as a second-line treatment in case of residual tumor regrowth. This resulted in an improvement of outcomes (0\% HB 5-6) despite the larger tumor sizes $(25 \pm 14 \mathrm{~mm}$ vs. $31 \pm 9 \mathrm{~mm}, p<0.05)$. Hearing preservation rates did not increase.

Conclusions Near-total resection and subsequent $\mathrm{CK}$ radiosurgery in case of residual tumor regrowth during follow-up seems to provide a good outcome of facial nerve function even in large VSs.
\end{abstract}

Keywords Vestibular schwannoma $\cdot$ Facial nerve $\cdot$ Hearing $\cdot$ Microsurgery $\cdot$ Retrosigmoid approach $\cdot$ Intraoperative monitoring

This article is part of the Topical Collection on Tumor - Schwannoma

\section{Nils Danner}

nils.danner@kuh.fi

1 Neurosurgery of Neurocenter, Kuopio University Hospital and Clinical Institute, University of Eastern Finland, P.O.B 100, 70029 KYS, Kuopio, Finland

2 Neurosurgery, Assiut University Hospital and Faculty of Medicine, Assiut University, Assiut, Egypt

3 Otorhinolaryngology, Kuopio University Hospital and Clinical Institute, University of Eastern Finland, Kuopio, Finland

4 Clinical Neurophysiology, Kuopio University Hospital and Clinical Institute, University of Eastern Finland, Kuopio, Finland

5 Clinical Neuropathology, Kuopio University Hospital and Clinical Institute, University of Eastern Finland, Kuopio, Finland

6 Neurosurgery, Tampere University Hospital, Tampere, Finland

\section{Introduction}

Vestibular schwannoma (VS), previously also called acoustic neuroma, is a benign, slow-growing tumor originating from the Schwann cells of the vestibular branch of the vestibulocochlear nerve [17]. The annual incidence of VS is 1-2:100,000 making it the third most common benign intracranial tumor. In its location, the cerebellopontine angle (CPA), VS is the most common type of tumor [25, 30, 37, 50]. The typical symptoms of VSs are caused by compression on the adjacent cranial nerves and may present as hearing loss, tinnitus, dizziness, facial numbness or weakness. Large VSs may even cause hydrocephalus or brainstem compression [14, 31]. Sporadic VSs are almost exclusively unilateral, whereas bilateral VSs are typically associated with neurofibromatosis type 2 (NF2) [3].

Since VSs are benign of nature, their treatment options are dependent on the symptoms caused by the tumor. Small VSs with mild symptoms may be followed-up by repeated 
MR-imaging, whereas larger tumors with pronounced symptoms or tumors with a rapid growth rate may warrant aggressive treatment. Treatment indications and modalities for VSs vary between different centers. The aim of VS surgery is maximum safe resection without causing additional neurological defects in the function of adjacent cranial nerves. In this perspective, the preservation of facial nerve function is crucial due to its location in the immediate proximity of the tumor. However, surgical treatment of VSs results in permanent facial weakness in $10-40 \%$ of patients $[15,54$, 63]. In order to minimize iatrogenic nerve injuries, intraoperative neurophysiological monitoring and direct nerve stimulation have become routine practice to aid the recognition and preservation of the cranial nerves during surgery $[1,43$, $58,60]$. Since small tumors have a better prognosis for facial nerve preservation after surgery some centers opt for an aggressive treatment scheme, whereas a more conservative approach with regular follow-ups allows the treatment to be targeted to tumors with growth tendency avoiding unnecessary surgeries and operative complications. Furthermore, the extent of resection is a matter of debate, since gross total resection (GTR) may impose a greater risk on the function of the facial nerve, whereas near-total (NTR) or subtotal resection (STR) may lead to tumor recurrence requiring reoperation or radiation therapy $[16,44,45,50]$.

The aim of the current study is to evaluate facial nerve function in a population-based series of consecutive patients operated for VS with intraoperative neurophysiological monitoring between the years 2001 and 2017. During the study period, the surgical strategy shifted from total to near-total resection with the aim of avoiding iatrogenic facial nerve paresis. The introduction of stereotactic Cyber Knife (CK) radiosurgery (Accuracy Inc., Sunnyvale, CA) led to a further paradigm shift in the treatment protocol by providing a second-line treatment option in the case of residual tumor growth. The purpose of the present study is to characterize factors, which influence the functional outcome of the facial nerve after VS surgery via the retrosigmoid approach in a center with routine intraoperative monitoring and access to CK radiosurgery.

\section{Patients and methods}

\section{Literature review}

PubMed was searched for original publications in the English language from the year 2000 onwards with the following search words: (vestibular or acoustic or acustic) and (schwannoma* or neuroma* or neurinoma*) and ((facial or seventh) and nerve)) and (monitoring or stimulation or mapping). Case reports, abstracts and articles with insufficient outcome data were further excluded. The results of all 29 relevant original publications reporting long-term results of over 100 patients are presented in Table $1[2,5-10,18,20-23,26-29$, $33,34,36,40,44,46,48,49,52,55,56,61,62]$.

\section{Patients}

A population-based cohort was retrospectively collected from the catchment area of Kuopio University Hospital comprising the population of Central and Eastern Finland with over 830,000 people (Statistics Finland). All patients were operated at the Neurocenter of Kuopio University Hospital. The operation journals and pathology databases were screened to find all operatively treated VSs between the years 2001 and 2017. The files of all patients were thoroughly reviewed and the MRIs re-evaluated. Tumor sizes were measured and classified according to the Koos grading [24]. Pre- and postoperative audiograms were re-evaluated and hearing was graded according to the EU classification [57]. Facial nerve function was evaluated according to the House-Brackmann scale [19].

\section{Treatment protocol}

All patients in the study were operated via the retrosigmoid approach. Neurophysiological monitoring was used to guide safe tumor resection. Continuous EMG-monitoring of $\mathrm{V}$ and VII cranial nerves was performed and direct nerve stimulation was routinely applied in all elective operations. Depending on the size of the tumor and the clinical situation, IX-XII cranial nerves were also monitored. The monitoring was performed by an experienced clinical neurophysiologist present at the operation. The monitoring system and setup varied during the study period and has been adjusted individually when needed. The surgical strategy was changed in case spontaneous EMG activity indicative of facial nerve damage was observed or if the stimulation threshold for eliciting motor evoked potentials increased [43]. In case the internal acoustic meatus was drilled in order to remove the intrameatal part of the tumor, an experienced surgeon in otorhinolaryngology was attending the operation in addition to the neurosurgeon.

From 2013 onwards, stereotactic CK radiosurgery was adapted as a part of the treatment protocol of VSs at Kuopio University Hospital. Between the years 2001 and 2012 (preCK era) the aim of surgery was gross-total resection of the tumor with drilling of the internal acoustic channel in order to completely remove also the intrameatal part of the tumor (preCK era). In the latter part of the study period, during the years 2013-2017 (post-CK era), the emphasis was shifted towards preserving the function of the facial nerve leading to a treatment strategy with near-total resection of the tumor $[38,47]$. A thin layer of tumor tissue was intentionally left on the adherent parts of the facial nerve and the internal acoustic meatus was not drilled. In case of residual tumor regrowth during 


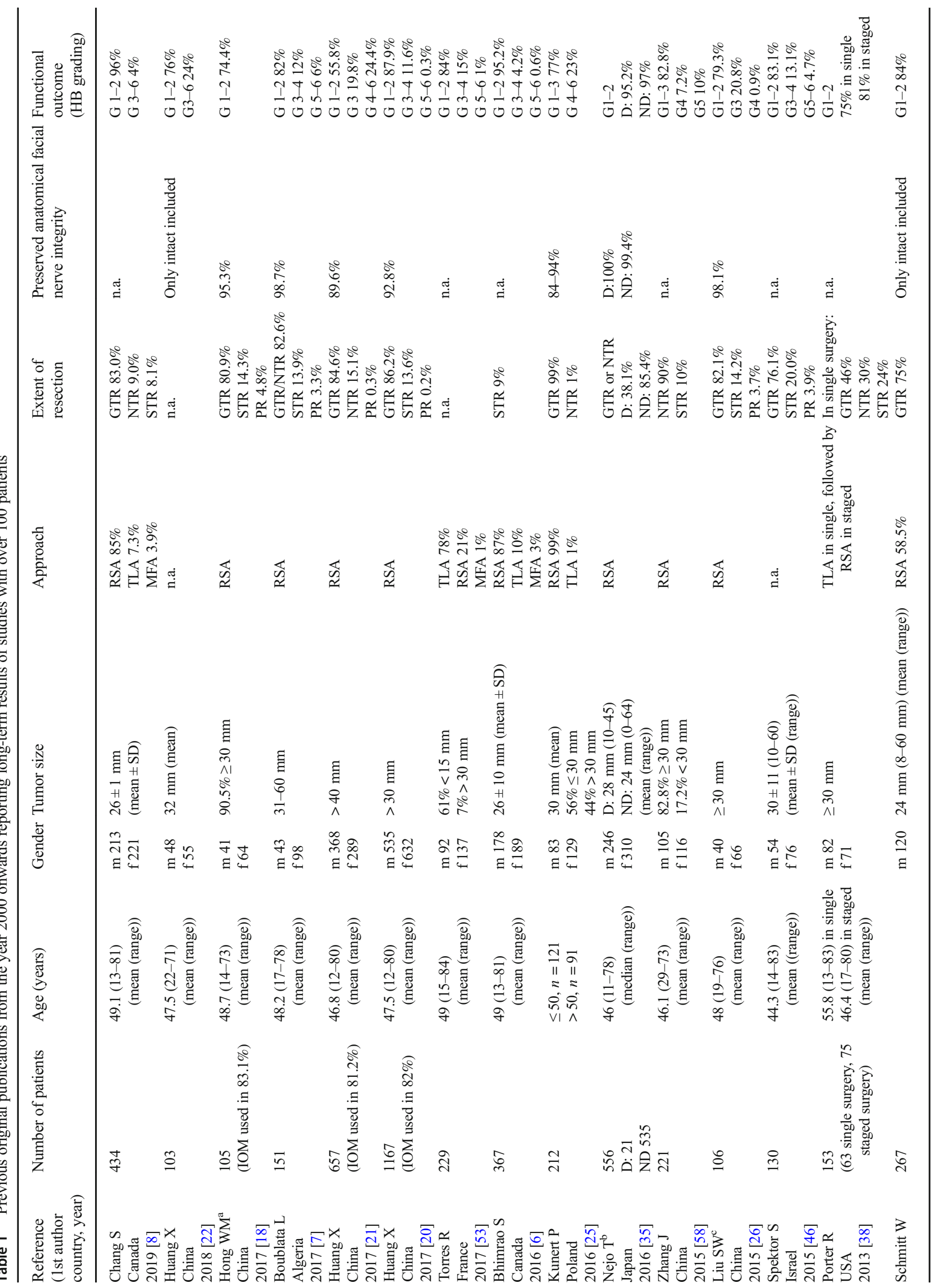




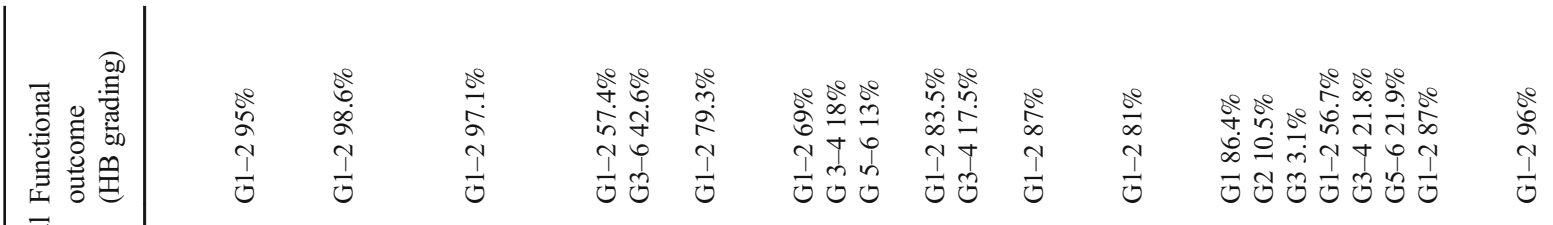

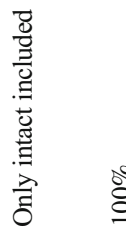

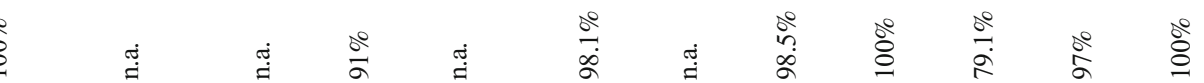

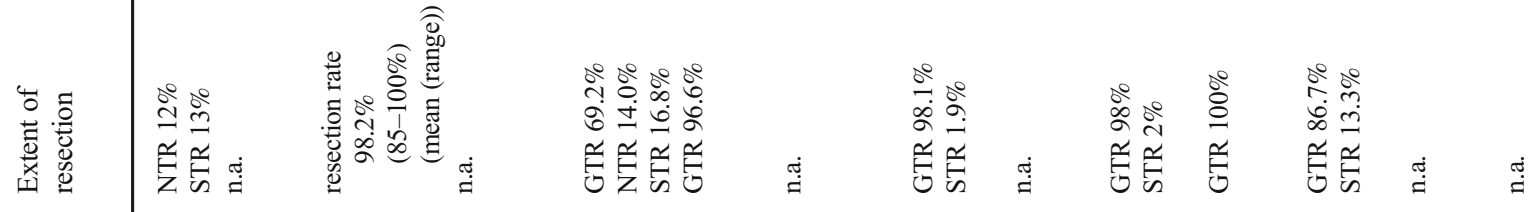

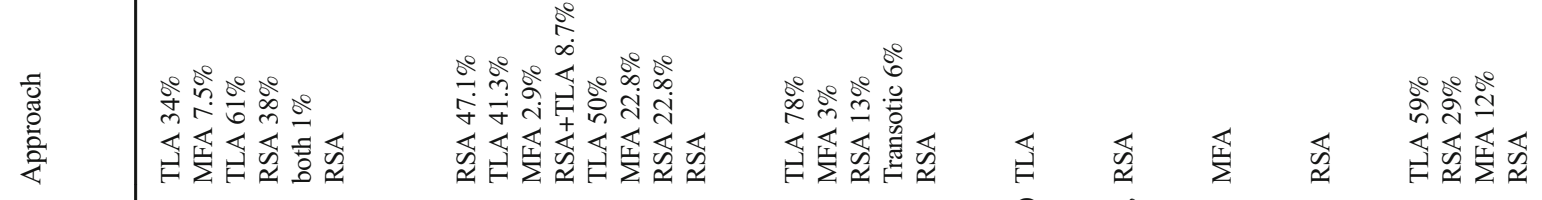

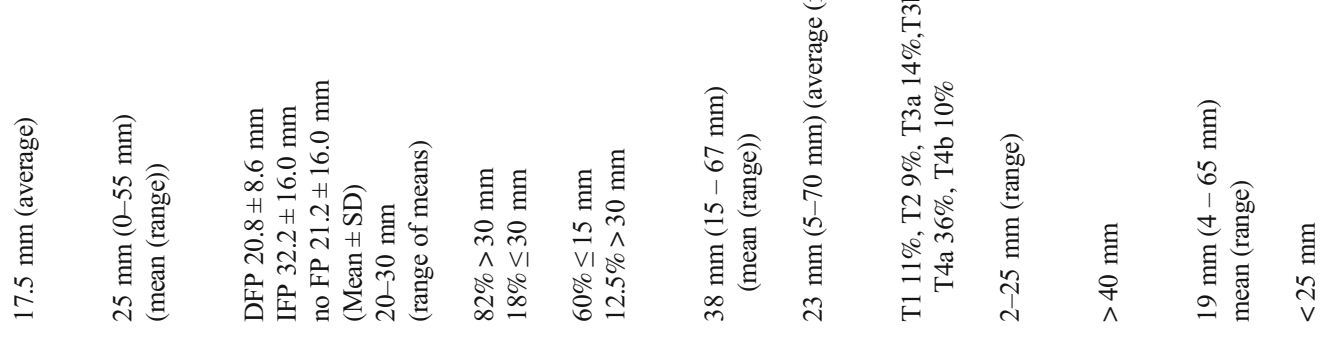

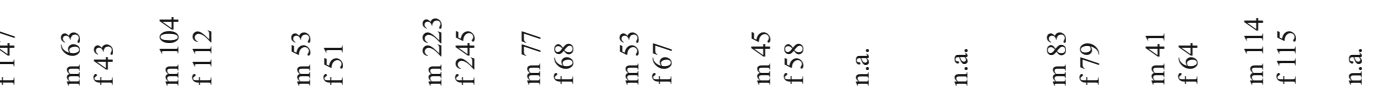

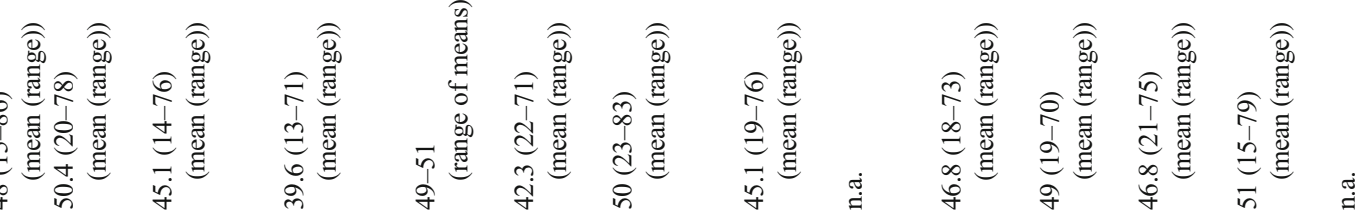
๖

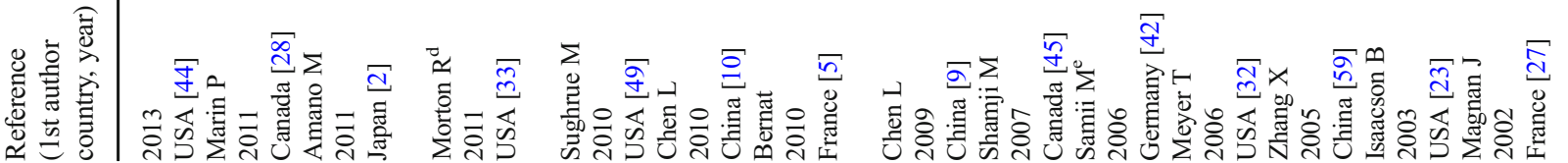


subsequent follow-up, CK radiosurgery was used as secondline treatment option.

\section{Follow-up}

Facial nerve function was followed up 12 months after the operation. Tumor residual and regrowth was evaluated by repetitive MRI scans. Data on mortality, reoperation, or adjuvant treatment with radiosurgery was collected until the end of the study period (follow-up time up to 16 years).

\section{Statistical methods}

For statistical analysis, nonparametric tests (Mann-Whitney, $\mathrm{chi}^{2}$, and Kruskal-Wallis) were used. For statistical significance, the $p$ level was set at 0.05 . A classification tree analysis was performed to evaluate the effect of patient-, tumor-, and treatment-related factors on the final outcome.

\section{Ethical aspects}

The study protocol was approved by the ethics committee of Kuopio University Hospital.

\section{Results}

A total number of 117 patients were operated during the study period. A flow chart of the patient recruitment is presented in Fig. 1. Nine patients with neurofibromatosis type 2, six patients with schwannomas of other than VIII cranial nerve were excluded from the analyses. Seven patients had had a previous operation before the beginning of the study period and were therefore excluded from the study. This resulted in a final study population of 95 patients with 37 males and 58 females with a median age of 54 years (range 19-79 years).

There was no perioperative mortality prior to discharge. Two patients died within 3 months following the operation and further two within 1 year. Three patients were lost before the end of the 1-year follow-up period.

The outcomes of the patients are presented in Table 2. In the total population, $67 \%$ of the patients had a good outcome (HB 1-2), $16 \%$ a moderate outcome (HB 3-4) and $17 \%$ a poor outcome (HB 5-6). Tumor sizes, diameters, and volumes differed significantly between the outcome groups $(p<0.05)$. In all patients with a poor outcome, the tumor was in contact with the brainstem or even compressing it. However, mean the Koos grades did not differ significantly between the outcome groups. The symptomatology of the patients showed also significant differences between the groups. Patients who exhibited a worse clinical outcome had more commonly clinical signs of brainstem and cerebellar compression as well as 
Fig. 1 Flow chart of the patient recruitment for the study
Patients identified $n=117$

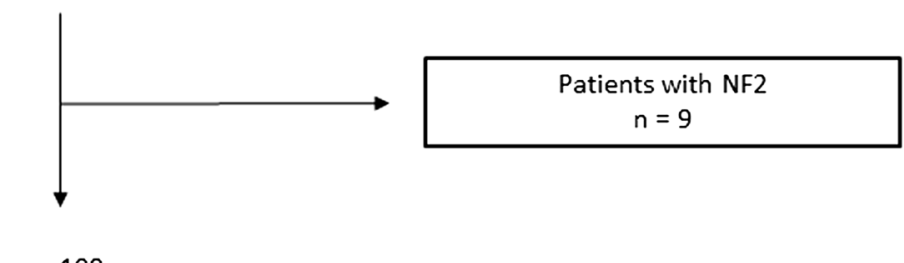

$n=108$

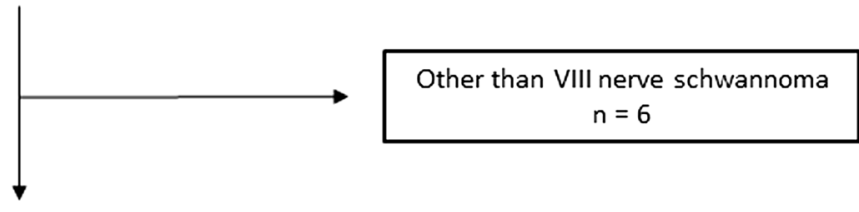

$n=102$

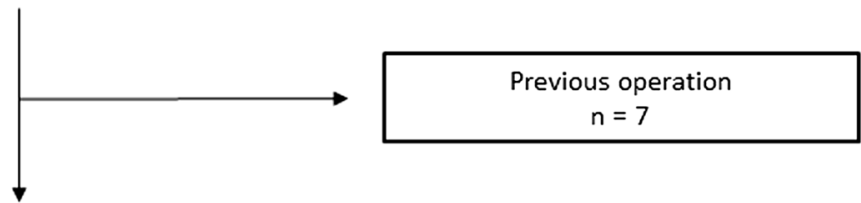

Final study population

$\mathrm{n}=95$ preoperative facial nerve dysfunction $(p<0.05)$. The extent of resection and complication rate did not differ between the outcome groups. However, in the poor outcome group, intraoperative neurophysiological monitoring indicated facial nerve damage in $40 \%$ of patients $(p<0.05)$. A classification tree analysis of outcomes is presented in Fig. 2. Preoperative audiograms were available for 63 patients and postoperative audiograms for 65 patients. Normal preoperative hearing (class I, $<20 \mathrm{~dB}$ ) was found in $23.8 \%$ of patients and $7.9 \%$ of patients were deaf on the affected side. Postoperatively, the hearing class remained unchanged in $16.0 \%$ of patients and improved in one patient. A decrease of two or more hearing classes was observed in $52.0 \%$ of patients and $66.2 \%$ were deaf (class $\mathrm{V},>95 \mathrm{~dB}$ ) on the operated side. The distribution of pre- and postoperative hearing is illustrated in Fig. 3 as decibels corresponding to the hearing classes.

Seventy-three patients were operated before the introduction of $\mathrm{CK}$ and 22 during the $\mathrm{CK}$ era (Table 3). Patient demographics did not differ between the groups. In the CK era, the extent of resection was targeted to the extrameatal part of the tumor in over $91 \%$ of cases as opposed to the pre CK era when the also intrameatal part of the tumor was removed in $58 \%$ of cases $(p<0.05)$. In the $\mathrm{CK}$ era, the diameters and volumes of the operated tumors were larger $(p<0.05)$ and all had a Koos grade 3 or 4 . Despite the larger tumor sizes, the facial nerve outcomes were better $(p<0.05)$ as compared to the pre CK era and there were no poor outcomes.

\section{Discussion}

This study presents the outcomes of patients operated due to vestibular schwannoma in a population-based non-selected cohort. All in all, $67 \%$ of patients achieved a good facial nerve outcome. According to the classification tree analysis, a good outcome rate of $90 \%$ was achieved if no stimulation threshold increase was observed during intraoperative monitoring, the size of the tumor was under $30 \mathrm{~mm}$ and no hydrocephalus was present (Fig. 2.). In a regression analysis, none of the parameters was found to be independently associated with either a good or a bad outcome. However, patients with a less favorable outcome had significantly larger tumors in terms of diameter and volume (Table 2.). In accordance, preoperative symptoms of brain stem compression due to larger tumors were more commonly associated with poor facial nerve outcomes. Unsurprisingly, preoperative facial nerve dysfunction was also more common in patients with a poor postoperative result. The results of the current study are in line with previous literature in terms of the postoperative facial nerve preservation rate, which decreases considerably with tumor size (Table 1).

Neuromonitoring with facial nerve stimulation has become an essential part of VS surgery during the past decades $[1,58]$. The use of monitoring has been shown to improve the outcome of surgery and, when indicating nerve damage, to have also a predictive value in terms of operative outcome $[2,4,29$, 
Table 2 Differences in clinical and operative parameters according to the outcome of facial nerve function after vestibular schwannoma surgery

\begin{tabular}{|c|c|c|c|c|}
\hline & $\begin{array}{l}\text { Good outcome } \\
\text { (HB 1-2) } \\
n=59(67 \%)\end{array}$ & $\begin{array}{l}\text { Moderate outcome } \\
\text { (HB 3-4) } \\
n=14(16 \%)\end{array}$ & $\begin{array}{l}\text { Poor outcome } \\
\text { (HB 5-6) } \\
n=15(17 \%)\end{array}$ & $\begin{array}{l}\text { Difference between } \\
\text { groups }\end{array}$ \\
\hline Age $($ mean $\pm \mathrm{SD})$ & $51 \pm 13$ years & $55 \pm 16$ years & $55 \pm 15$ years & \\
\hline Gender (male/female) & $20 / 39$ & $7 / 7$ & $6 / 9$ & \\
\hline \multicolumn{4}{|l|}{$\operatorname{Size}^{1}$} & \multirow[t]{5}{*}{$\mathrm{p}<0.05$} \\
\hline Intrameatal & $2(4.1 \%)$ & $1(7.1 \%)$ & $1(7.7 \%)$ & \\
\hline Small & $6(12.2 \%)$ & $1(7.1 \%)$ & - & \\
\hline Medium & $31(63.3 \%)$ & $4(28.6 \%)$ & $5(38.5 \%)$ & \\
\hline Large & $10(20.4 \%)$ & $8(57.1 \%)$ & $7(53.8 \%)$ & \\
\hline $\begin{array}{l}\text { Largest diameter }{ }^{2} \\
(\text { mean } \pm \mathrm{SD} \text {, range }) \\
\text { Volume }^{2} \\
(\text { mean } \pm \mathrm{SD} \text {, range }) \\
\text { Koos grade } \\
\text { (mean } \pm \mathrm{SD} \text {, range) } \\
\text { Clinical presentation }\end{array}$ & $\begin{array}{l}24 \pm 12 \mathrm{~mm} \\
0-53 \mathrm{~mm} \\
9000 \pm 11,000 \mathrm{~mm}^{3} \\
26-49,000 \mathrm{~mm}^{3} \\
3.4 \pm 0.9 \\
1-4\end{array}$ & $\begin{array}{l}33 \pm 10 \mathrm{~mm} \\
0-51 \mathrm{~mm} \\
16,000 \pm 11,000 \mathrm{~mm}^{3} \\
3200-34,000 \mathrm{~mm}^{3} \\
3.6 \pm 0.6 \\
2-4\end{array}$ & $\begin{array}{l}32 \pm 15 \mathrm{~mm} \\
0-50 \mathrm{~mm} \\
17,000 \pm 21,000 \mathrm{~mm}^{3} \\
2700-47,000 \mathrm{~mm}^{3} \\
3.8 \pm 0.4 \\
3-4\end{array}$ & $\begin{array}{l}\mathrm{p}<0.05 \\
\mathrm{p}<0.05\end{array}$ \\
\hline Hydrocephalus & $7(11.9 \%)$ & $4(28.6 \%)$ & $5(33.3 \%)$ & \\
\hline Headache & $9(15.3 \%)$ & $4(28.6 \%)$ & $5(33.3 \%)$ & \\
\hline Vertigo & $35(59.3 \%)$ & $6(42.9 \%)$ & $6(40.0 \%)$ & \\
\hline Imbalance/ataxia & $12(20.3 \%)$ & $5(35.7 \%)$ & $9(60.0 \%)$ & $\mathrm{p}<0.01$ \\
\hline Hearing & $51(86.4 \%)$ & $11(78.6 \%)$ & $14(93.3 \%)$ & \\
\hline Tinnitus & $19(32.2 \%)$ & $3(21.4 \%)$ & $6(40.0 \%)$ & \\
\hline Facial & $1(1.7 \%)$ & $2(14.3 \%)$ & $3(20.0 \%)$ & $\mathrm{p}<0.05$ \\
\hline Trigeminal & $15(25.4 \%)$ & $3(21.4 \%)$ & $2(13.3 \%)$ & \\
\hline Brainstem/cerebellar & $5(8.5 \%)$ & $1(7.1 \%)$ & $5(33.3 \%)$ & $\mathrm{p}<0.05$ \\
\hline \multicolumn{5}{|c|}{ Hearing class ${ }^{3}$ (mean, range) } \\
\hline Preoperative & $2.4(1-5)$ & $2.6(1-3)$ & $3.3(2-5)$ & \\
\hline Postoperative & $4.1(1-5)$ & $4.2(1-5)$ & $5.0(5)$ & \\
\hline Change & 1.8 & 1.6 & 2.3 & \\
\hline \multicolumn{5}{|l|}{ Extent of resection } \\
\hline Gross total & $17(29.3 \%)$ & $4(28.6 \%)$ & $5(33.3 \%)$ & \\
\hline Near total & $35(60.3 \%)$ & $10(71.4 \%)$ & $7(46.7 \%)$ & \\
\hline Subtotal & $6(10.3 \%)$ & - & $2(13.3 \%)$ & \\
\hline Partial & - & - & $1(6.7 \%)$ & \\
\hline Drilling $^{4}$ & $28(48.3 \%)$ & $7(50.0 \%)$ & $7(46.7 \%)$ & \\
\hline Threshold increase $\mathrm{e}^{5}$ & $2(2.3 \%)$ & $2(16.7 \%)$ & $4(66.7 \%)$ & $\mathrm{p}<0.001$ \\
\hline Loss of response $\mathrm{s}^{5}$ & - & $2(15.4 \%)$ & $3(37.5 \%)$ & $\mathrm{p}<0.01$ \\
\hline Complication $^{6}$ & $4(6.8 \%)$ & $2(14.3 \%)$ & $4(26.7 \%)$ & \\
\hline Regrowth $^{7}$ & $12(20.3 \%)$ & $3(23.1 \%)$ & $6(40.0 \%)$ & \\
\hline
\end{tabular}

Differences between groups were tested using the Kruskall-Wallis test and the chi square test. Significant differences have been indicated. Valid percentages of available data are reported for each parameter

${ }^{1}$ Size is determined according to largest extrameatal diameter (small $\leq 15 \mathrm{~mm}, 15 \mathrm{~mm}<$ medium $\leq 30 \mathrm{~mm}$, large $>30 \mathrm{~mm}$ )

${ }^{2}$ Diameter and volume are calculated for the extrameatal part of the tumor

${ }^{3}$ Koos grading of vestibular schwannoma: 1 , intrameatal; 2, extending to the cerebellopontine angle; 3 , in contact with the brainstem; 4, compressing the brainstem

${ }^{4}$ Hearing is determined according to the WHO classification

${ }^{5}$ Drilling of internal acoustic meatus

${ }^{6}$ Intraoperative increase in stimulation threshold or loss of response in facial nerve monitoring

${ }^{7}$ Postoperative complication requiring re-operation

${ }^{8}$ Regrowth during subsequent follow-up leading to intervention 


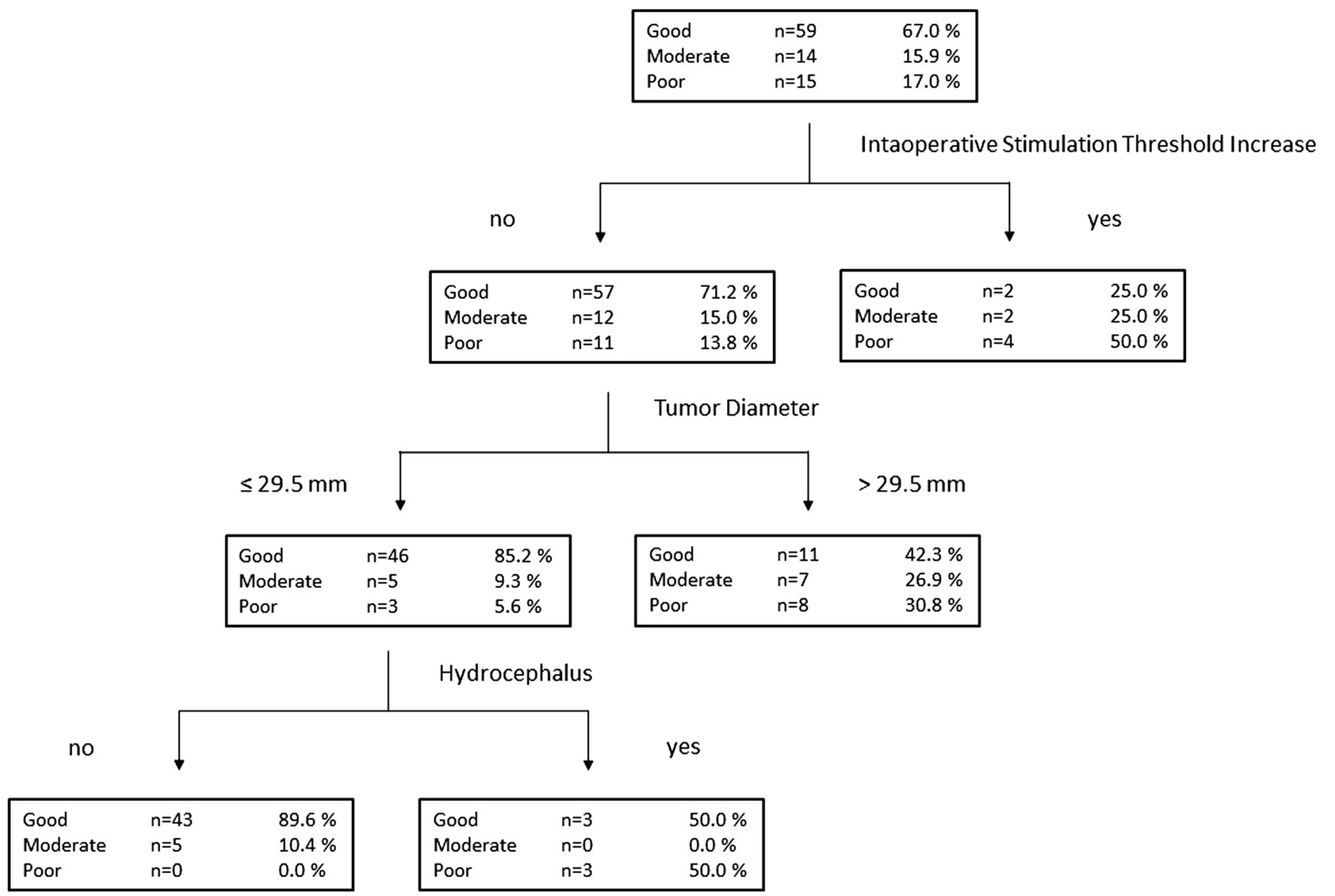

Fig. 2 Classification tree analysis of outcome at 1 year after vestibular schwannoma surgery

Fig. 3 Hearing in the ipsilateral ear of individual patients in decibels $(\mathrm{dB})$ corresponding to the hearing classes $(1-5)$ before and after vestibular schwannoma surgery

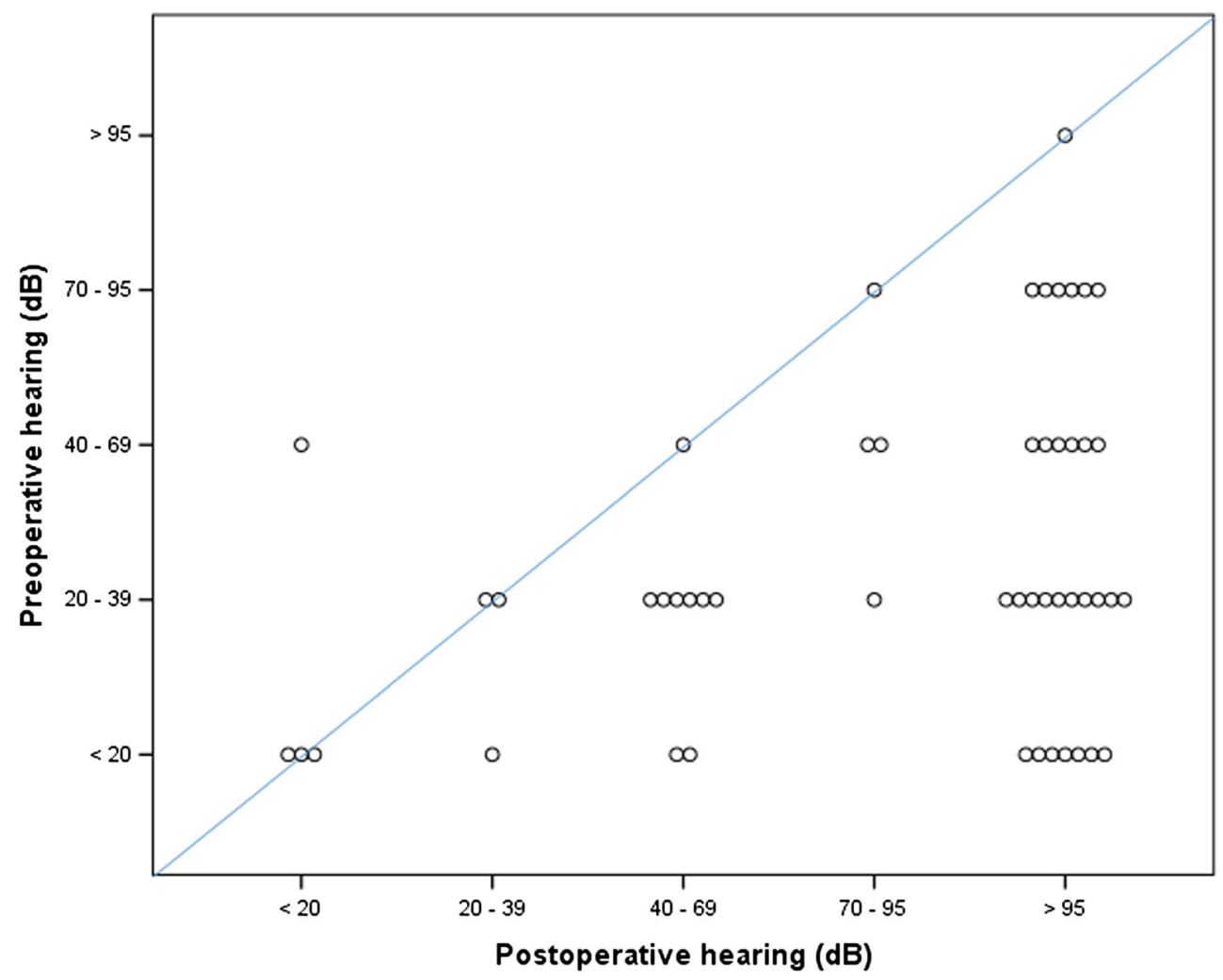


Table 3 Clinical parameters and outcomes of vestibular schwannoma surgery before and after treatment paradigm change with the introduction of Cyber Knife (CK) radiosurgery

\begin{tabular}{|c|c|c|c|}
\hline & $\begin{array}{l}\text { Before CK }(n=73) \\
2001-2012\end{array}$ & $\begin{array}{l}\text { After CK }(n=22) \\
2013-2017\end{array}$ & \\
\hline Age (mean \pm sd) & $53 \pm 14$ years & $52 \pm 16$ years & \\
\hline Gender (male/female) & $30 / 43$ & $7 / 15$ & \\
\hline Diameter (mean \pm sd) & $25 \pm 14 \mathrm{~mm}$ & $31 \pm 9 \mathrm{~mm}$ & $\mathrm{p}<0.05$ \\
\hline Volume (mean $\pm \mathrm{sd})$ & $10,400 \pm 12,100 \mathrm{~mm}^{3}$ & $14,100 \pm 11,400 \mathrm{~mm}^{3}$ & $\mathrm{p}<0.05$ \\
\hline \multicolumn{4}{|l|}{ Size $^{1}$} \\
\hline Intrameatal & $6.6 \%(n=4)$ & - & \\
\hline Small & $11.5 \%(n=7)$ & - & \\
\hline Medium & $50.8 \%(n=31)$ & $54.5 \%(n=12)$ & \\
\hline Large & $31.1 \%(n=19)$ & $45.5 \%(n=10)$ & \\
\hline Koos grade $(\text { mean } \pm \text { sd }(\text { range }))^{2}$ & $3.32 \pm 0.81(1-4)$ & $3.95 \pm 0.21(3-4)$ & \\
\hline Extent of resection & & & $\mathrm{p}<0.01$ \\
\hline Gross total & $36.1 \%(n=26)$ & $9.1 \%(n=2)$ & \\
\hline Near total & $47.2 \%(n=34)$ & $90.9 \%(n=20)$ & \\
\hline Subtotal & $13.9 \%(n=10)$ & - & \\
\hline Partial & $2.8 \%(n=2)$ & - & \\
\hline Drilling $^{3}$ & $58.3 \%(n=42)$ & $9.1 \%(n=2)$ & $\mathrm{p}<0.001$ \\
\hline Complication $^{4}$ & $15.1 \%(n=11)$ & $4.5 \%(n=1)$ & \\
\hline Regrowth $^{5}$ & $24.7 \%(n=18)$ & $19.8 \%(n=4)$ & \\
\hline Facial nerve outcome ${ }^{6}$ & & & $\mathrm{p}<0.05$ \\
\hline Good & $65.2 \%(n=43)$ & $68.4 \%(n=13)$ & \\
\hline Moderate & $12.1 \%(n=8)$ & $31.6 \%(n=6)$ & \\
\hline Poor & $22.8 \%(n=15)$ & - & \\
\hline \multicolumn{4}{|l|}{ Hearing class $(\text { mean } \pm S D)^{7}$} \\
\hline Preoperative & $2.5 \pm 1.2$ & $2.6 \pm 1.5$ & \\
\hline Postoperative & $4.2 \pm 1.3$ & $4.3 \pm 0.9$ & \\
\hline Change & $1.7 \pm 1.4$ & $2.0 \pm 1.5$ & \\
\hline
\end{tabular}

Significant differences have been indicated according to the Mann-Whintey $U$ and chi square test

${ }^{1}$ Size is determined according to largest diameter (small $\leq 15 \mathrm{~mm}<$ medium $\leq 30 \mathrm{~mm}<$ large)

${ }^{2}$ Koos grading of vestibular schwannoma: 1 , intarmeatal; 2 , extending to the cerebellopontine angle; 3 , in contact with the brainstem; 4 , compressing the brainstem

${ }^{3}$ Drilling in internal acoustic meatus

${ }^{4}$ Complication requiring re-operation

${ }^{5}$ Regrowth leading to reoperation or radiosurgery

${ }^{6}$ Facial nerve outcome at 12 months by House-Brackman grade (1-2 good, 3-4 moderate, 5-6 poor)

${ }^{7}$ Hearing is determined according to the WHO classification

52]. In the current study, this predictive value was evident, since in the good outcome group, only two patients exhibited an intraoperative stimulation threshold increase, whereas nearly $70 \%$ of patients in the poor outcome group showed signs of facial nerve damage during surgery (Table 2 and Fig. 2). In addition to direct facial nerve stimulation, the pattern of spontaneous EMG activity during the operation has also been applied to guide tumor resection and shown to obtain predictive value. However, the interpretation of spontaneous EMG activity is more complex, since only specific wave forms and trains have been reported to associate to $\mathrm{FN}$ damage $[35,41$,
43]. Spontaneous EMG activity was not evaluated in the current study, since the actual recording data was not available in retrospect.

Hearing impairment is the most common initial symptom of VS and the natural course has been shown to lead to nonseviceable hearing in $50 \%$ of patients over a 5 -year period in patients with good initial hearing [39, 42, 53]. Accordingly, hearing is impaired in most patients already before surgery. However, in patients with good initial hearing and small tumor size, up to over $60 \%$ have been reported to have good or serviceable postoperative hearing [32], whereas in larger 
tumors the percentage is far lower especially if hearing is affected already preoperatively [59]. In the current study, hearing was impaired in most patients already preoperatively and only $23.8 \%$ had normal hearing on the affected side. Postoperatively, $18 \%$ of patients retained or improved their hearing class and $66.2 \%$ were deaf. Hearing outcome did not correlate with facial nerve outcome (Table 2 and Fig. 3). Thus, in large VSs, operative treatment cannot be justified with the aim of hearing preservation.

Since total resection of especially large VSs carries a considerable risk of facial nerve injury and hearing defect, a less radical treatment paradigm has been introduced during the recent years. After planned sub-total surgical resection combined with adjuvant radiosurgery, better outcomes have been reported in terms of hearing and facial nerve preservation as well as tumor control $[11-13,51]$. During the current study period, the introduction of CK radiosurgery changed the treatment protocol of VSs also at our institution. The operative paradigm shifted to near-total resection and subsequent $\mathrm{CK}$ radiosurgery in the case of regrowth during follow-up. This resulted in significantly improved postoperative facial nerve outcomes, since no poor outcomes were seen after the paradigm shift despite the larger tumor sizes (Table 3). In addition, the immediate postoperative complication rate was lower, although not statistically significant. However, in the current study population the change in the treatment paradigm did not improve hearing outcomes. The tumor regrowth percentage was rather similar in the pre- and post-CK era. This may suggest a higher regrowth percentage after near-total resection, since the follow-up period was shorter for the patients treated during the latter period. However, the availability of second-line CK-radiosurgery may have led to treatment of smaller-sized tumor regrowth as compared to the pre-CK era. Furthermore, in addition to the difference in the length of the follow-up, the number of patients operated during the CK era was less than one third that in the pre CK era, and therefore no definite conclusions can yet be drawn on the regrowth rate of the residual tumor.

\section{Conclusions}

In this study we present the facial nerve and hearing outcomes after VS surgery in an unselected population-based cohort. An operative treatment paradigm with near-total resection of the tumor and subsequent CK radiosurgery in case of residual tumor regrowth during follow-up seems to result in a better functional outcome of the facial nerve.

Acknowledgements Dr. Ismail Taha wishes to acknowledge Professor Radwan Nouby and Dr. Wael M. A. Abdel Ghani from Assiut University, Egypt, for supporting his research fellowship at Kuopio University Hospital.
Funding Information Open access funding provided by University of Eastern Finland (UEF) including Kuopio University Hospital.

\section{Compliance with ethical standards}

Conflict of interest The authors declare that they have no competing interests.

Ethical approval All procedures performed in studies involving human participants were in accordance with the ethical standards of the institutional and/or national research committee (name of institute/committee) and with the 1964 Helsinki declaration and its later amendments or comparable ethical standards. For this type of study, formal consent is not required.

Open Access This article is distributed under the terms of the Creative Commons Attribution 4.0 International License (http:// creativecommons.org/licenses/by/4.0/), which permits unrestricted use, distribution, and reproduction in any medium, provided you give appropriate credit to the original author(s) and the source, provide a link to the Creative Commons license, and indicate if changes were made.

\section{References}

1. Acioly MA, Liebsch M, de Aguiar PH, Tatagiba M (2013) Facial nerve monitoring during cerebellopontine angle and skull base tumor surgery: a systematic review from description to current success on function prediction. World Neurosurg 80:e271-e300. https://doi.org/10.1016/j.wneu.2011.09.026

2. Amano M, Kohno M, Nagata O, Taniguchi M, Sora S, Sato H (2011) Intraoperative continuous monitoring of evoked facial nerve electromyograms in acoustic neuroma surgery. Acta Neurochir 153: 1059-1067; discussion 1067. https://doi.org/10.1007/s00701-0100937-6

3. Asthagiri AR, Parry DM, Butman JA, Kim HJ, Tsilou ET, Zhuang Z, Lonser RR (2009) Neurofibromatosis type 2. Lancet 373:19741986. https://doi.org/10.1016/S0140-6736(09)60259-2

4. Axon PR, Ramsden RT (1999) Intraoperative electromyography for predicting facial function in vestibular schwannoma surgery. Laryngoscope 109:922-926

5. Bernat I, Grayeli AB, Esquia G, Zhang Z, Kalamarides M, Sterkers O (2010) Intraoperative electromyography and surgical observations as predictive factors of facial nerve outcome in vestibular schwannoma surgery. Otol Neurotol 31:306-312. https://doi.org/ 10.1097/MAO.0b013e3181be6228

6. Bhimrao SK, Le TN, Dong CC, Makarenko S, Wongprasartsuk S, Westerberg BD, Akagami R (2016) Role of facial nerve motorevoked potential ratio in predicting facial nerve function in vestibular schwannoma surgery both immediate and at 1 year. Otol Neurotol 37:1162-1167. https://doi.org/10.1097/MAO. 0000000000001137

7. Boublata L, Belahreche M, Ouchtati R, Shabhay Z, Boutiah L, Kabache M, Nadji M, Djenna Z, Bounecer H, Ioualalen N (2017) Facial nerve function and quality of resection in large and Giant vestibular schwannomas surgery operated by Retrosigmoid Transmeatal approach in semi-sitting position with intraoperative facial nerve monitoring. World Neurosurg 103:231-240. https:// doi.org/10.1016/j.wneu.2017.02.053

8. Chang S, Makarenko S, Despot I, Dong C, Westerberg BD, Akagami R (2019) Differential recovery in early- and late-onset delayed facial palsy following vestibular schwannoma resection. Oper Neurosurg (Hagerstown). https://doi.org/10.1093/ons/opz083 
9. Chen L, Chen L, Liu L, Ling F, Yuan X, Fang J, Liu Y (2009) Vestibular schwannoma microsurgery with special reference to facial nerve preservation. Clin Neurol Neurosurg 111:47-53. https:// doi.org/10.1016/j.clineuro.2008.07.012

10. Chen L, Chen LH, Ling F, Liu YS, Samii M, Samii A (2010) Removal of vestibular schwannoma and facial nerve preservation using small suboccipital retrosigmoid craniotomy. Chin Med J 123: 274-280

11. Chen Z, Prasad SC, Di Lella F, Medina M, Piccirillo E, Taibah A, Russo A, Yin S, Sanna M (2014) The behavior of residual tumors and facial nerve outcomes after incomplete excision of vestibular schwannomas. J Neurosurg 120:1278-1287. https://doi.org/10. 3171/2014.2.JNS131497

12. Daniel RT, Tuleasca C, George M, Pralong E, Schiappacasse L, Zeverino M, Maire R, Levivier M (2017) Preserving normal facial nerve function and improving hearing outcome in large vestibular schwannomas with a combined approach: planned subtotal resection followed by gamma knife radiosurgery. Acta Neurochir 159: 1197-1211. https://doi.org/10.1007/s00701-017-3194-0

13. Daniel RT, Tuleasca C, Rocca A, George M, Pralong E, Schiappacasse L, Zeverino M, Maire R, Messerer M, Levivier M (2018) The changing paradigm for the surgical treatment of large vestibular schwannomas. J Neurol Surg B Skull Base 79:S362S370. https://doi.org/10.1055/s-0038-1668540

14. Foley RW, Shirazi S, Maweni RM, Walsh K, McConn Walsh R, Javadpour M, Rawluk D (2017) Signs and symptoms of acoustic neuroma at initial presentation: an exploratory analysis. Cureus 9: e1846. https://doi.org/10.7759/cureus.1846

15. Gurgel RK, Dogru S, Amdur RL, Monfared A (2012) Facial nerve outcomes after surgery for large vestibular schwannomas: do surgical approach and extent of resection matter? Neurosurg Focus 33: E16. https://doi.org/10.3171/2012.7.FOCUS12199

16. Gurgel RK, Theodosopoulos PV, Jackler RK (2012) Subtotal/neartotal treatment of vestibular schwannomas. Curr Opin Otolaryngol Head Neck Surg 20:380-384. https://doi.org/10.1097/MOO. 0b013e328357b220

17. Hilton DA, Hanemann CO (2014) Schwannomas and their pathogenesis. Brain Pathol 24:205-220. https://doi.org/10.1111/bpa. 12125

18. Hong W, Cheng H, Wang X, Feng C (2017) Influencing factors analysis of facial nerve function after the microsurgical resection of acoustic neuroma. J Korean Neurosurg Soc 60:165-173. https:// doi.org/10.3340/jkns.2013.0407.001

19. House JW, Brackmann DE (1985) Facial nerve grading system. Otolaryngol Head Neck Surg 93:146-147. https://doi.org/10. 1177/019459988509300202

20. Huang X, Xu J, Xu M, Chen M, Ji K, Ren J, Zhong P (2017) Functional outcome and complications after the microsurgical removal of giant vestibular schwannomas via the retrosigmoid approach: a retrospective review of 16-year experience in a single hospital. BMC Neurol 17:18. https://doi.org/10.1186/s12883-0170805-6

21. Huang X, Xu M, Xu J, Zhou L, Zhong P, Chen M, Ji K, Chen H, Mao Y (2017) Complications and Management of Large Intracranial Vestibular Schwannomas via the Retrosigmoid approach. World Neurosurg 99:326-335. https://doi.org/10.1016/j. wneu.2016.12.055

22. Huang X, Ren J, Xu J, Xu M, Chen D, Chen M, Ji K, Wang H, Chen H, Cao L, Shao Y, Zhong P, Ballena R, Zhou L, Mao Y (2018) The utility of "low current" stimulation threshold of intraoperative electromyography monitoring in predicting facial nerve function outcome after vestibular schwannoma surgery: a prospective cohort study of 103 large tumors. J Neuro-Oncol 138:383-390. https://doi. org/10.1007/s11060-018-2806-8
23. Isaacson B, Kileny PR, El-Kashlan H, Gadre AK (2003) Intraoperative monitoring and facial nerve outcomes after vestibular schwannoma resection. Otol Neurotol 24:812-817

24. Koos WT, Day JD, Matula C, Levy DI (1998) Neurotopographic considerations in the microsurgical treatment of small acoustic neurinomas. J Neurosurg 88:506-512. https://doi.org/10.3171/jns. 1998.88.3.0506

25. Kshettry VR, Hsieh JK, Ostrom QT, Kruchko C, Barnholtz-Sloan JS (2015) Incidence of vestibular schwannomas in the United States. J Neuro-Oncol 124:223-228. https://doi.org/10.1007/ s11060-015-1827-9

26. Kunert P, Dziedzic T, Nowak A, Czernicki T, Marchel A (2016) Surgery for sporadic vestibular schwannoma. Part I: general outcome and risk of tumor recurrence. Neurol Neurochir Pol 50:83-89. https://doi.org/10.1016/j.pjnns.2016.01.001

27. Liu SW, Jiang W, Zhang HQ, Li XP, Wan XY, Emmanuel B, Shu K, Chen JC, Chen J, Lei T (2015) Intraoperative neuromonitoring for removal of large vestibular schwannoma: facial nerve outcome and predictive factors. Clin Neurol Neurosurg 133:83-89. https://doi. org/10.1016/j.clineuro.2015.03.016

28. Magnan J, Barbieri M, Mora R, Murphy S, Meller R, Bruzzo M, Chays A (2002) Retrosigmoid approach for small and mediumsized acoustic neuromas. Otol Neurotol 23:141-145

29. Marin P, Pouliot D, Fradet G (2011) Facial nerve outcome with a peroperative stimulation threshold under $0.05 \mathrm{~mA}$. Laryngoscope 121:2295-2298. https://doi.org/10.1002/lary.22359

30. Marinelli JP, Lohse CM, Carlson ML (2018) Incidence of vestibular schwannoma over the past half-century: a population-based study of Olmsted County, Minnesota. Otolaryngol Head Neck Surg: 194599818770629. https://doi.org/10.1177/0194599818770629

31. Matthies C, Samii M (1997) Management of 1000 vestibular schwannomas (acoustic neuromas): clinical presentation. Neurosurgery 40:1-9 discussion 9-10

32. Mazzoni A, Zanoletti E, Calabrese V (2012) Hearing preservation surgery in acoustic neuroma: long-term results. Acta Otorhinolaryngol Ital 32:98-102

33. Meyer TA, Canty PA, Wilkinson EP, Hansen MR, Rubinstein JT, Gantz BJ (2006) Small acoustic neuromas: surgical outcomes versus observation or radiation. Otol Neurotol 27:380-392

34. Morton RP, Ackerman PD, Pisansky MT, Krezalek M, Leonetti JP, Raffin MJ, Anderson DE (2011) Prognostic factors for the incidence and recovery of delayed facial nerve palsy after vestibular schwannoma resection. J Neurosurg 114:375-380. https://doi.org/ 10.3171/2010.5.JNS091854

35. Nakao Y, Piccirillo E, Falcioni M, Taibah A, Kobayashi T, Sanna M (2001) Electromyographic evaluation of facial nerve damage in acoustic neuroma surgery. Otol Neurotol 22:554-557

36. Nejo T, Kohno M, Nagata O, Sora S, Sato H (2016) Dorsal displacement of the facial nerve in acoustic neuroma surgery: clinical features and surgical outcomes of 21 consecutive dorsal pattern cases. Neurosurg Rev 39:277-288; discussion 288. https://doi.org/ 10.1007/s10143-015-0681-8

37. Ostrom QT, Gittleman H, Liao P, Rouse C, Chen Y, Dowling J, Wolinsky Y, Kruchko C, Barnholtz-Sloan J (2014) CBTRUS statistical report: primary brain and central nervous system tumors diagnosed in the United States in 2007-2011. Neuro Oncol 16(Suppl 4):iv1-63. https://doi.org/10.1093/neuonc/nou223

38. Park CK, Jung HW, Kim JE, Son YJ, Paek SH, Kim DG (2006) Therapeutic strategy for large vestibular schwannomas. J NeuroOncol 77:167-171. https://doi.org/10.1007/s11060-005-9015-y

39. Pinna MH, Bento RF, Neto RV (2012) Vestibular schwannoma: 825 cases from a 25-year experience. Int Arch Otorhinolaryngol 16: 466-475. https://doi.org/10.7162/S1809-97772012000400007

40. Porter RG, LaRouere MJ, Kartush JM, Bojrab DI, Pieper DR (2013) Improved facial nerve outcomes using an evolving 
treatment method for large acoustic neuromas. Otol Neurotol 34: 304-310

41. Prell J, Rachinger J, Scheller C, Alfieri A, Strauss C, Rampp S (2010) A real-time monitoring system for the facial nerve. Neurosurgery 66:1064-1073; discussion 1073. https://doi.org/10. 1227/01.NEU.0000369605.79765.3E

42. Reznitsky M, Caye-Thomasen P (2019) Systematic review of hearing preservation in observed vestibular schwannoma. J Neurol Surg B Skull Base 80:165-168. https://doi.org/10.1055/s-0039-1679894

43. Romstock J, Strauss C, Fahlbusch R (2000) Continuous electromyography monitoring of motor cranial nerves during cerebellopontine angle surgery. J Neurosurg 93:586-593. https:// doi.org/10.3171/jns.2000.93.4.0586

44. Samii M, Gerganov V, Samii A (2006) Improved preservation of hearing and facial nerve function in vestibular schwannoma surgery via the retrosigmoid approach in a series of 200 patients. J Neurosurg 105:527-535. https://doi.org/10.3171/jns.2006.105.4. 527

45. Sarmiento JM, Patel S, Mukherjee D, Patil CG (2013) Improving outcomes in patients with vestibular schwannomas: microsurgery versus radiosurgery. J Neurosurg Sci 57:23-44

46. Schmitt WR, Daube JR, Carlson ML, Mandrekar JN, Beatty CW, Neff BA, Driscoll CL, Link MJ (2013) Use of supramaximal stimulation to predict facial nerve outcomes following vestibular schwannoma microsurgery: results from a decade of experience. $\mathrm{J}$ Neurosurg 118:206-212. https://doi.org/10.3171/2012.10. JNS12915

47. Seol HJ, Kim CH, Park CK, Kim CH, Kim DG, Chung YS, Jung HW (2006) Optimal extent of resection in vestibular schwannoma surgery: relationship to recurrence and facial nerve preservation. Neurol Med Chir (Tokyo) 46:176-180; discussion 180-171. https://doi.org/10.2176/nmc.46.176

48. Shamji MF, Schramm DR, Benoit BG (2007) Clinical predictors of facial nerve outcome after translabyrinthine resection of acoustic neuromas. Clin Invest Med 30:E233-E239

49. Spektor S, Fraifeld S, Margolin E, Saseedharan S, Eimerl D, Umansky F (2015) Comparison of outcomes following complex posterior fossa surgery performed in the sitting versus lateral position. J Clin Neurosci 22:705-712. https://doi.org/10.1016/j.jocn. 2014.12.005

50. Stangerup SE, Caye-Thomasen P (2012) Epidemiology and natural history of vestibular schwannomas. Otolaryngol Clin N Am 45(257-268):vii. https://doi.org/10.1016/j.otc.2011.12.008

51. Starnoni D, Daniel RT, Tuleasca C, George M, Levivier M, Messerer M (2018) Systematic review and meta-analysis of the technique of subtotal resection and stereotactic radiosurgery for large vestibular schwannomas: a "nerve-centered" approach. Neurosurg Focus 44:E4. https://doi.org/10.3171/2017.12. FOCUS17669

52. Sughrue ME, Kaur R, Kane AJ, Rutkowski MJ, Kaur G, Yang I, Pitts LH, Parsa AT (2010) The value of intraoperative facial nerve electromyography in predicting facial nerve function after vestibular schwannoma surgery. J Clin Neurosci 17:849-852. https://doi. org/10.1016/j.jocn.2010.02.003
53. Sughrue ME, Yang I, Aranda D, Lobo K, Pitts LH, Cheung SW, Parsa AT (2010) The natural history of untreated sporadic vestibular schwannomas: a comprehensive review of hearing outcomes. J Neurosurg 112:163-167. https://doi.org/10.3171/2009.4. JNS08895

54. Sughrue ME, Yang I, Rutkowski MJ, Aranda D, Parsa AT (2010) Preservation of facial nerve function after resection of vestibular schwannoma. Br J Neurosurg 24:666-671. https://doi.org/10. 3109/02688697.2010.520761

55. Tonn JC, Schlake HP, Goldbrunner R, Milewski C, Helms J, Roosen K (2000) Acoustic neuroma surgery as an interdisciplinary approach: a neurosurgical series of 508 patients. J Neurol Neurosurg Psychiatry 69:161-166

56. Torres R, Nguyen Y, Vanier A, Smail M, Ferrary E, Sterkers O, Kalamarides M, Bernardeschi D (2017) Multivariate analysis of factors influencing facial nerve outcome following microsurgical resection of vestibular schwannoma. Otolaryngol Head Neck Surg 156:525-533. https://doi.org/10.1177/0194599816677711

57. Uimonen S, Maki-Torkko E, Jounio-Ervasti K, Sorri M (1997) Hearing in 55 to 75 year old people in northern Finland-a comparison of two classifications of hearing impairment. Acta Otolaryngol Suppl 529:69-70

58. Vivas EX, Carlson ML, Neff BA, Shepard NT, McCracken DJ, Sweeney AD, Olson JJ (2018) Congress of Neurological Surgeons systematic review and evidence-based guidelines on intraoperative cranial nerve monitoring in vestibular schwannoma surgery. Neurosurgery 82:E44-E46. https://doi.org/10.1093/ neuros/nyx 513

59. Wanibuchi M, Fukushima T, McElveen JT Jr, Friedman AH (2009) Hearing preservation in surgery for large vestibular schwannomas. $\mathrm{J}$ Neurosurg 111:845-854. https://doi.org/10.3171/2008.12. JNS08620

60. Youssef AS, Downes AE (2009) Intraoperative neurophysiological monitoring in vestibular schwannoma surgery: advances and clinical implications. Neurosurg Focus 27:E9. https://doi.org/10.3171/ 2009.8.FOCUS09144

61. Zhang X, Fei Z, Chen YJ, Fu LA, Zhang JN, Liu WP, He XS, Jiang XF (2005) Facial nerve function after excision of large acoustic neuromas via the suboccipital retrosigmoid approach. J Clin Neurosci 12:405-408. https://doi.org/10.1016/j.jocn.2004.03.042

62. Zhang J, Xu BN, Hou YZ, Sun GC, Jiang Y (2015) Facial and Cochlear nerve complications following microsurgical resection of vestibular schwannomas in a series of 221 cases. Med Sci Monit 21:1674-1678. https://doi.org/10.12659/MSM.892607

63. Zou P, Zhao L, Chen P, Xu H, Liu N, Zhao P, Lu A (2014) Functional outcome and postoperative complications after the microsurgical removal of large vestibular schwannomas via the retrosigmoid approach: a meta-analysis. Neurosurg Rev 37:1521. https://doi.org/10.1007/s10143-013-0485-7

Publisher's note Springer Nature remains neutral with regard to jurisdictional claims in published maps and institutional affiliations. 